\title{
ECONOMIC GEOGRAPHY AND \\ THE FISCAL EFFECTS OF REGIONAL INTEGRATION
}

\author{
RODNEY D. LUDEMA* \\ Department of Economics \\ Georgetown University \\ Washington DC 20057, USA
}

\section{IAN WOOTON}

\author{
Department of Economics \\ University of Glasgow \\ Glasgow G12 8RT, UK
}

\author{
Centre for Economic Policy Research \\ 90-98 Goswell Road \\ London ECIV 7DB, UK
}

\begin{abstract}
In models of economic geography, plant-level scale economies and trade costs create incentives for spatial agglomeration of production into a manufacturing core and agricultural periphery, creating regional income differentials. We examine tax competition between national governments to influence the location of manufacturing activity. Labour is imperfectly mobile and governments impose redistributive taxes. Regional integration is modeled as either increased labour mobility or lower trade costs. We show that either type of integration may result in a decrease in the intensity of tax competition, and thus higher equilibrium taxes. Moreover, economic integration must increase taxes when the forces of agglomeration are the strongest.
\end{abstract}

Keywords: economic integration, economic geography, factor mobility, international trade; tax competition

JEL codes: F12, F15, F22, H73 


\section{Introduction}

Two related issues arise frequently in discussions of economic integration. One is the erosion of fiscal autonomy that countries may experience when economic integration leads to a more mobile tax base. The other is the possibility of integration leading to spatial agglomeration of economic activity with divergent economic structures and incomes across the integrating countries. The former issue touches upon an extensive theoretical literature on tax competition, begun by Oates (1972), Wilson (1987), Wildasin (1988), and others, and applied to economic integration by Persson and Tabellini (1992). ${ }^{1}$ The latter issue stems from the recent literature known as the "new economic geography", pioneered by Krugman (e.g., Krugman, 1991a, 1991b, 1993; Venables, 1994; Martin and Rogers, 1995). ${ }^{2}$ The two issues are related by the idea that economic integration may give rise to a greater propensity for factors of production to relocate and take advantage of international differences in taxation or real incomes. To our knowledge, however, the relationship between these two issues has never been examined formally. This paper attempts to fill this gap.

The new geography literature relies heavily on Krugman (1991a), which develops a two-location, two-good model involving labour mobility, plant-level scale economies, and trade (e.g., transport) costs. Scale economies in manufacturing (the other sector is agriculture) lead each firm to concentrate its production in a single location from which it exports. The firm's preferred location will tend to be the larger of the two markets, as locating there minimises its trade costs. These trade costs also mean that workers (who are also consumers) prefer to live in the country with more firms, as it offers better access to manufactured goods. Together, these two aspects, which Krugman identifies as "backward" and "forward" linkages, respectively, work to produce the spatial agglomeration of activity into a manufacturing "core" and an agricultural "periphery". The only brake on this process comes from the demand for manufactures by immobile agricultural factors left behind in the 
periphery. Remarkably, lowering (but not eliminating) trade costs increases the tendency for the core-periphery pattern to emerge.

Arising from these results is the implication that economic integration is likely to be a politically charged issue, being particularly unpopular with immobile factors stranded in the periphery. Consequently, such factors will have an incentive to compete for the core, using whatever policies they have available. Krugman (1991b) has interpreted Canada's National Policy of the late-nineteenth century in these terms, arguing that it was successful in creating a Canadian manufacturing core. While Canada's National Policy relied heavily on tariffs, there are many settings where trade restrictions are infeasible, such as the European Union or NAFTA. Indeed, trade barrier reductions are at the heart of the economic integration efforts of these regions. However, countries usually have access to other policies that can exert substantial influence on the location of economic activity, such as taxes, subsidies, public goods provision and the like. Here, we focus on competition between national governments using tax policies to influence the location of manufacturing activity. ${ }^{3}$

Tax competition between governments introduces an additional mechanism by which regional integration can have distributional consequences. While agglomeration may alter the distribution of income across countries, tax competition influences the distribution of income across factors. If immobile factors compete to create or maintain a core by offering low (or negative) taxes to mobile manufacturing labour, they run the risk that much of the potential gain to having a core is dissipated in the process. If so, then agglomerative forces coupled with the tax competition may impoverish immobile factors, regardless of location. Thus, the foremost question we shall address in this paper is whether economic integration, by strengthening agglomerative forces, intensifies tax competition and results in lower equilibrium taxes?

The literature on tax competition is well-developed but generally not directed toward questions of economic integration per se. One notable exception is Persson and Tabellini 
(1992), which considers the effects of integration on tax competition, but takes integration to mean an increase in the mobility of factors rather than of goods. In that model, capital is the mobile factor, with its ownership distributed across the population, and taxes are set by the median voter. Integration intensifies tax competition (lowers taxes), in so far as it makes capital more responsive to tax incentives, but it also shifts the median voter to the "left", which mitigates the tax reduction.

In this paper, we construct a variant of the economic geography model of Krugman (1991a). Whereas Krugman uses (Dixit-Stiglitz) monopolistic competition to model the structure of the manufactures market, we use a simple homogeneous-product oligopoly. This specification preserves all of the relevant characteristics of Krugman's model while resulting in a dramatic simplification in algebra. While Krugman's model is highly non-linear and requires numerical simulation to get even the most basic of results, our model produces closed-form solutions that are easy to interpret and manipulate. Unlike Krugman, we additionally allow for the imperfect mobility of manufacturing labour. This enables us to model economic integration as either an increase in factor mobility or as a reduction in trade costs on goods.

We follow Persson and Tabellini (1992) in that we seek to explain the fiscal response of the two countries to economic integration and we assume taxes exist only to redistribute income, so as to abstract from the efficiency considerations of public-goods provision. However, unlike them, we assume ownership of factors to be highly concentrated and that the owners of immobile factors are politically decisive. Thus, the objectives of the governments remain fixed throughout the exercise.

What we had expected to find in this setting was that economic integration would increase the intensity of tax competition, thereby lowering the taxes on mobile factors at the expense of immobile factors. Our intuition was based on the notion that integration, whether in the form of a reduced trade cost (which increases the relative strength of agglomerative forces) or increased labour mobility, would have two consequences. Firstly, integration would 
cause labour to become more responsive to tax differentials between the two countries. Secondly, and as a result, countries would be more apt to cut taxes (or raises subsidies) on manufacturing labour. As it turns out, both of these predictions may be false.

We show that integration makes labour more responsive to tax differentials only when agglomerative forces are too weak or labour is insufficiently mobile for the core-periphery pattern to emerge as an equilibrium. If there exists a core-periphery equilibrium, then integration makes labour less responsive to tax differentials. The reason is that, once workers are all concentrated in a core, any measure that increases agglomerative forces (such as a reduction in the trade cost) or increases worker mobility only makes them more inclined to stay where they are.

Our main result is, however, that economic integration, in form of a reduction in trade costs, may reduce the intensity of tax competition regardless of whether labour becomes more or less responsive to tax differentials. Furthermore, this type of integration must increase taxes when the forces of agglomeration are the strongest. The reason has to do with one of the key agglomerative forces at work in the model-the forward linkage, or what we call (somewhat unimaginatively) the "consumer price effect" of emigration. When workers leave a country (due to a tax increase, for example), domestic production in the country of emigration falls, foreign production rises, and domestic consumers become more reliant on imports. Because imports are subject to trade costs, this raises the domestic consumer price. A reduction in the trade cost reduces this consumer price effect, and, as a result, countries find it less costly to raise taxes.

The remainder of the paper is organised as follows. In section 2 we present a model of geography based on Krugman (1991a). This model exhibits the agglomerative forces described earlier and produces a relationship between the after-tax real wage differential and the allocation of labour across the two countries, which we call the labour-demand schedule. We introduce a model of imperfect labour mobility in section 3 , from which we produce a 
labour-supply schedule. The properties of various equilibria are discussed in Section 4. Section 5 contains our analysis of tax competition in the two major classes of equilibria: the diversified case, where no core-periphery pattern emerges; and the concentrated case, where a core-periphery pattern must emerge. These two cases are then linked to provide a complete picture of taxation in the various stages of economic integration. Section 6 concludes.

\section{Economic Geography and the Demand for Manufacturing Labour}

Consider a world consisting of two countries, 1 and 2, and a continuum of individuals. The measure of the world population is taken to be 1. The population is divided into two groups, farmers and manufacturing workers, with the share of manufacturing workers in the world population being given exogeneously by $\mu>0$.

Farmers are specific to the production of an homogeneous agricultural good, which is taken as the numeraire. We assume constant returns to scale and a unit input requirement equal to one in this sector. Thus the income of each farmer is one, and worldwide agricultural income (in the absence of taxes) is $(1-\mu)$. The agricultural good is freely tradable, while the farmers themselves are assumed to be internationally immobile. Half of the farmers are assumed to reside in country 1 and half in country 2 .

Manufacturing workers are specific to the production of an homogeneous manufactured good and the workers are assumed to be mobile between the two countries. We assume that each individual must work, consume, and pay taxes in the same location. This distinguishes the model from one of capital mobility, in which factor supply and consumption can be geographically separated. It also assumes residence-based, rather than citizenshipbased, taxation. ${ }^{4}$ Let the variable $f$ denote the fraction of manufacturing workers in country 1.

In addition to a mobile work force, the manufacturing sector features increasing returns, imperfect competition, and trade costs. To produce any of the manufactured good, a firm must incur the fixed cost of hiring a positive measure $\beta<\mu$ of the manufacturing workers. 
For simplicity, the marginal cost of production is constant and equal to zero. Assuming fullemployment and free entry, the number of manufacturing firms world-wide is $n=\mu / \beta$, and the manufacturing wage in each country is equal to the operating profit of each local firm, divided by $\beta$. The $n$ firms are assumed to be quantity-setting (Cournot) oligopolists in the goods market. The manufactured good is assumed to be internationally tradable, subject to a trade $\operatorname{cost} \tau$. That is, a firm incurs a cost $\tau$ on each unit of the manufactured good it ships abroad.

All individuals share the same quasi-linear utility function:

$$
u=\left(a-\frac{x^{d}}{2}\right) x^{d}+y
$$

where $x^{d}$ and $y$ are individual consumption levels of the manufacturing and agricultural goods, respectively, and $a>0$. Thus, total demand for manufactures in country $i(i=1,2)$ is given by

$$
X_{i}^{d}=\left(a-p_{i}\right) s_{i}
$$

where $p_{i}$ and $s_{i}$ denote the price of manufactures and the share of the world's consumers, respectively, in country $i$. We refer to $s_{i}$ as country $i$ 's "market size" and note that $s_{i}$ depends upon $f$ according to: $s_{1}=f \mu+(1-\mu) / 2$ and $s_{2}=(1-f) \mu+(1-\mu) / 2$.

The operating profit of a representative firm is

$$
\pi_{i}=p_{i} x_{i i}+\left(p_{j}-\tau\right) x_{i j}, \quad(i=1,2 ; i \neq j)
$$

where $x_{i j}$ is the quantity that a country $i$ firm sells in country $j$. The firm's quantity choices satisfy the following first-order conditions:

$$
\begin{gathered}
x_{i i}=s_{i} p_{i}, \\
x_{i j}=s_{j}\left(p_{j}-\tau\right) .
\end{gathered}
$$

Thus, the wage in country $i$ is

$$
w_{i}=\frac{s_{i} p_{i}^{2}+s_{j}\left(p_{j}-\tau\right)^{2}}{\beta} .
$$


For the manufactures market to clear it must be that $X_{i}^{d}=n_{i} x_{i i}+n_{j} x_{j i}$, where $n_{i}$ is the number of firms located in country $i$. Note that $n_{i}$ depends upon $f$ according to: $n_{1}=f n$ and $n_{2}=(1-f) n$. Imposing market-clearing on (2), (4) and (5) yields the equilibrium price,

$$
p_{i}=\frac{a+\tau n_{j}}{1+n}
$$

We make the assumption that the trade cost is non-prohibitive for all $f$, or $\tau<a /(1+n)$.

Before proceeding further with the analysis, let us examine the effect of labour migration on a country's wage, as determined by equations (6) and (7). It follows from (7) that $p_{i} \geq p_{j}-\tau$, regardless of the allocation of workers across the two countries. In other words, domestic sales generate more revenue than foreign sales on average. Thus equation (6) implies that, at constant goods' prices, a country's manufacturing wage increases as workers immigrate, because immigration increases the country's domestic market size and decreases the size of the foreign market. Krugman (1980) has referred to this as the "home market effect." However, if we allow prices to change, there emerges another, possibly countervailing, effect. As workers immigrate, existing domestic firms will face more competitors in their domestic market and fewer in the foreign market. From (7), the domestic price must fall and the foreign price must rise. The impact of this "competition effect" (to continue using Krugman's terminology) on domestic wages depends on the relative market sizes, but for equal market sizes the effect is negative.

Both the competition and home market effects rely upon the presence of the trade cost. To identify which effect is dominant for different levels of the trade cost, we examine the manufacturing wage differential:

$$
w(f) \equiv w_{1}-w_{2}=(2 f-1)\left(\frac{n \tau}{1+n}\right)\left[2 a-\left(\frac{\mu+n}{\mu}\right) \tau\right] .
$$

The wage differential is zero when half of the labour force resides in each country and may be increasing or decreasing in $f$. For trade costs greater than $2 a \mu /(\mu+n)$, the competition effect 
dominates, and the wage differential falls as workers move to country 1 . For trade costs below $2 a \mu /(\mu+n)$, the home-market effect dominates, and the wage differential rises as workers move to country 1 . If the trade cost is zero, the wage differential is zero for all $f$.

Note that the critical trade cost, $2 a \mu /(\mu+n)$, depends negatively on $n$ and positively on $a$ and on $\mu$. The larger is $n$, the greater will be the effect of an increase in $f$ on the allocation of firms, and thus the greater the competition effect. The larger is $\mu$ the greater will be the effect of an increase in $f$ on the allocation of consumers, and thus the greater the homemarket effect. A higher value of $a$ leads to an overall higher price level, thus also contributing to the home-market effect.

Having described the effect of factor migration on the manufacturing wage, we now examine a second factor determining worker location: the utility derived from consumption in the two countries. The consumer surplus of an individual in country $i$ is given by

$$
c_{i}=\frac{\left(a-p_{i}\right)^{2}}{2}
$$

and the consumer-surplus differential is

$$
c(f) \equiv c_{1}-c_{2}=(2 f-1) \frac{n^{2} \tau}{(1+n)^{2}}\left(a-\frac{\tau}{2}\right) .
$$

This is increasing in $f$ for all non-prohibitive values of $\tau$. We shall refer to the increase in the consumer-surplus differential caused by an increase in a country's labour share as the consumer-price effect. The consumer-price effect is the consumption counterpart of the competition effect. As manufacturing workers migrate, the firms that move with them expand their sales in the country of immigration, as such sales are no longer subject to the trade cost. This drives down the price and raises the consumer surplus in the country of immigration. The opposite occurs in the country of emigration.

As our final component of labour demand, we assume that national governments impose a head tax on local manufacturing workers. ${ }^{5}$ Let $t_{i}$ be the tax levied in country $i$. 
Adding together (8), (10), and the tax differential $\left(t_{2}-t_{1}\right)$, we arrive at an after-tax real wage differential of

where

$$
\begin{gathered}
v(f)=(2 f-1) \kappa(\tau)+\left(t_{2}-t_{1}\right), \\
\kappa(\tau) \equiv\left(\frac{n \tau}{1+n}\right)\left[\frac{(3 n+2)(2 a-\tau)}{2(1+n)}-\frac{n \tau}{\mu}\right] .
\end{gathered}
$$

We refer to (11) as the labour-demand schedule. An upward-sloping labour-demand schedule will tend to contribute to agglomeration because, if more than half of the labour force locates in, say, country 1 , the real wage differential will be positive. Should workers move to country 1 to take advantage of the higher real wage, then the differential would grow and encourage even more immigration.

The slope of the labour-demand schedule is $2 \kappa(\tau)$, which is a quadratic function of the trade cost. Setting $\kappa(\tau)=0$, we find the critical trade cost,

$$
\tau^{*}=\frac{2 a \mu(2+3 n)}{\mu(2+3 n)+2 n(1+n)}
$$

This is the trade cost below which the consumer-price and home-market effects come to dominate the competition effect and the labour-demand schedule begins to slope upwards. The trade cost which maximizes $\kappa(\tau)$ is $\tau^{*} / 2$. For all $\tau$ between $\tau^{*} / 2$ and $\tau^{*}$, the slope of the labour demand schedule rises as the trade cost is reduced. The agglomerative forces can be said to be strengthened by trade liberalization within this range of $\tau$. Below $\tau * / 2, \kappa(\tau)$ falls as $\tau$ is reduced and ultimately becomes zero. Thus, our first conclusion about economic integration is that reductions in the trade cost do not continually increase the relative strength of agglomerative forces, but do so only up to a point, beyond which the agglomerative forces wane.

To reinforce the point, figure 1 shows the slope of the labour-demand curve, along with its components, as a function of the trade cost. The curve $w^{\prime}$ is the slope of (8) and 
measures the sum of the home-market and competition effects. The curve $c^{\prime}$ is the slope of (10), which is the consumer-price effect.

\section{Locational Preferences and The Supply of Manufacturing Labour}

While the real wage differential is a central element of a worker's locational decision, the manufacturing worker is also assumed to have preferences about location per se. Why a worker prefers one country or other is not explicitly modeled, but what we have in mind are such considerations as language and culture. These, it is often argued, account for the relative immobility of labour between EU countries, despite the virtual absence of formal barriers. ${ }^{6}$

A worker's locational preference is described by a single individual-specific parameter: let $\gamma_{\varphi}$ be worker $\varphi$ 's disutility from living in country 1 . Worker $\varphi$ will be indifferent between the two locations when the real wage differential equals this locational disutility, that is when:

$$
v=\gamma_{\varphi}
$$

We assume that workers' preferences are distributed uniformly ${ }^{7}$ on the interval $[-\lambda, \lambda]$. The fraction of the labour force with locational disutility less than or equal to $\gamma$ is given by:

$$
F(\gamma ; \lambda)=\left\{\begin{array}{cc}
0, & \gamma<-\lambda ; \\
\frac{\gamma+\lambda}{2 \lambda}, & -\lambda \leq \gamma \leq \lambda ; \\
1, & \gamma>\lambda .
\end{array}\right.
$$

The distribution of $\gamma$ is symmetric around 0 , with variance $\lambda^{2} / 3$. The term $\lambda$ can be interpreted as a measure of labour immobility between the two countries. If $\lambda$ is close to zero, then virtually the entire population is indifferent as to where it lives, and thus any real wage differential will induce workers to move. If $\lambda$ is large, then there are workers who would suffer a large disutility from living in their less preferred country. Such workers would require a large real wage differential to induce them to move from their preferred country.

Let $\theta$ denote the value of $\gamma_{\varphi}$ that satisfies equation (13). A worker with preference $\theta$ is marginal, in the sense that all workers for whom $\gamma_{\varphi}>\theta$ will choose to live and work in 
country 2 and all workers for whom $\gamma_{\varphi}<\theta$ will choose to live and work in country 1 . The fraction of manufacturing workers in country 1 is therefore $f=F(\theta ; \lambda)$. Inverting this gives:

$$
\theta(f)=(2 f-1) \lambda
$$

The term $\theta(f)$ can be interpreted as the real wage premium that country 1 must pay to induce the marginal worker to relocate. We shall refer to (15) as the labour-supply schedule. This has slope of $2 \lambda$ which is independent of the trade cost $\tau$. A lower $\lambda$ (that is, higher labour mobility) produces a more elastic supply schedule.

\section{Locational Equilibrium}

We have now established a labour-demand schedule, showing the relationship between the fraction of manufacturing labour in country 1 and the relative after-tax real wage. We have also found the willingness of workers to take employment in country 1 , which depends on the distribution of preferences over locations. Our next task is to determine the equilibrium employment pattern, given these preferences, the tax rates imposed by each country, and the level of trade costs.

It is a very convenient feature of our model that both the labour-supply and labourdemand schedules are linear in $f$. This means there are basically only two types of equilibria that can arise, depending upon which schedule has the greater slope. If $\lambda>\kappa(\tau)$, labour supply is steeper than labour demand, then there is generically a unique equilibrium, with manufacturing production diversified across the two countries. If $\lambda<\kappa(\tau)$, labour demand is the steeper of the two, and there will typically be two equilibria, with production concentrated in either one country or the other. These two types are illustrated in figure 2.

A diversified equilibrium occurs where $v(f)=\theta(f)$, which is where the after-tax real wage differential is exactly equal to the wage premium demanded by the marginal worker. If $\lambda>\kappa(\tau)$, then such an equilibrium is unique, as any smaller $f$ would cause the wage differential 
to exceed the premium (an thus all workers would prefer country 1), while any larger $f$ would have to the opposite effect. As illustrated in figure 2a, if taxes are the same in each country, the equilibrium is at point $\mathrm{A}$, with half of the manufacturing workers located in each country. With a positive tax differential, the labour-demand schedule is shifted up, and the equilibrium moves to point $\mathrm{A}^{\prime}$. Though it is possible for the tax differential to be so large as to drive the equilibrium into one of the corners, this does not occur in the symmetric tax-competition game of the next section. Thus, it is with only a slight abuse of terminology that we refer to all equilibria in which $\lambda>\kappa(\tau)$ as diversified.

If labour demand is steeper than labour supply, then there are multiple equilibria, two of which are concentrated. An equilibrium occurs at $f=0$ if $v(0) \leq \theta(0)$. In that case, the after-tax real wage differential is lower than the necessary wage premium for all workers. Thus, even the worker who most prefers to live in country 1 remains in country 2. Similarly, an equilibrium occurs at $f=1$ if $v(1) \geq \theta$ (1).

There may also be an interior equilibrium at which $v(f)=\theta(f)$. Krugman (1991) rules out such equilibria, on the grounds that they are "unstable" when $\lambda<\kappa(\tau)$. Although no explicit dynamic process is specified, the idea is that if workers always move in the direction of the location with the higher real wage (net of tax and locational preference), then any perturbation of $f$ would cause workers to move toward one corner or the other. While we wish to avoid, as much as possible, making assumptions about the transitional behaviour of workers, we follow Krugman in ruling out interior equilibria when $\lambda<\kappa(\tau)$.

As shown in figure $2 b$, if taxes are the same in each country, then there are two equilibria, A and B. At point A, country 2 is the core, and country 1 is the periphery. The opposite is true at point B. As before, a positive tax differential shifts the labour demand schedule upwards. For small tax differentials, there will continue to be two concentrated equilibria, but if $t_{2}-t_{1}$ becomes large enough, there will only one equilibrium which is 
concentrated in country 1 . Figure $2 b$ illustrates the tax differential which is just on the margin. Points $\mathrm{A}^{\prime}$ and $\mathrm{B}^{\prime}$ are both equilibria, but any higher tax differential would produce a unique equilibrium directly above B'.

There is a third possible case we have not yet mentioned, that of $\lambda=\kappa(\tau)$, when the labour-demand and labour-supply schedules have exactly the same slope. In such a case, if the tax rates were the same in each country, then any allocation of manufacturing labour would constitute an equilibrium. However, any tax differential would produce a unique concentrated equilibrium in the country with the lower tax rate. For our purposes, this case is no different from the concentrated case examined in figure $2 b$, and henceforth we shall not distinguish between them.

Because of the linearity of the model the foregoing list of cases is exhaustive. Had we used more complicated functional forms on either the demand side (as in Krugman, 1991a) or the supply side (such as some alternative distribution of locational preferences), we might have encountered cases in which the two schedules cross each other more than once. Ludema and Wooton (1997) examine multiple-crossing cases in some detail. These cases can be quite complicated, and the complexity becomes overwhelming when tax competition is introduced. For this reason, we have designed this model to avoid cases of multiple crossings.

\section{Tax Competition}

We assume that all revenue from a country's tax on manufacturing workers is distributed lump-sum to the country's farmers. Thus, total agricultural welfare in each country is

$$
\begin{gathered}
u_{1}^{A}=\left(\frac{1-\mu}{2}\right)\left(c_{1}+1\right)+t_{1} \mu f, \\
u_{2}^{A}=\left(\frac{1-\mu}{2}\right)\left(c_{2}+1\right)+t_{2} \mu(1-f) .
\end{gathered}
$$

The objective of the government of country $i$ is to maximize $u_{i}^{A}$ using its tax rate. The game is the usual two-stage affair: in the first stage, governments simultaneously choose tax rates; in 
the second stage, firms, workers, and consumers make their economic choices taking the tax rates as given. The solution will be a subgame-perfect Nash equilibrium.

There is little to justify our assumption about the government objective, other than to say that it enables us to make our point as succinctly as possible. If we were to allow manufacturing workers to have some weight in the government objective, there might be some interesting wrinkles along the lines of Persson and Tabellini (1992), but the basic results, we conjecture, would remain the same. If we were to assume $\mu<1 / 3$, then agricultural workers would constitute the majority in each country, regardless of the allocation of manufacturing workers between countries. In that case, equating the government objective with real agricultural income would be sensible.

\subsection{Tax Competition with Diversification}

Suppose that $\lambda>\kappa(\tau)$, so that the labour supply schedule is steeper than the labour-demand schedule and the equilibrium is diversified. The effect of an increase in country 1's tax rate on agricultural welfare is

$$
\frac{d u_{1}^{A}}{d t_{1}}=\mu f+t_{1} \mu \frac{d f}{d t_{1}}+\frac{\tau n(1-\mu)\left(a-p_{1}\right)}{2(1+n)} \frac{d f}{d t_{1}}
$$

The tax increase has three effects on agricultural welfare, evident in the three terms of (18). The first two are the usual ones: the first is positive and represents the increase in revenue from raising the tax rate on a given tax base, while the second represents the negative effect on revenue of a reduction in the tax base as workers flee the country. The magnitude of the second effect depends on the level of the tax and on the reduction in $f$ brought about by the increased tax. The third term is the negative effect of the tax on consumer surplus. The tax increase causes the country to lose not only workers but also domestic production, thus forcing the country into an increased reliance on imports. This drives up the country's price level and reduces the consumer surplus of the farmers. 
The two negative terms of (18) depend on the magnitude of the reduction in $f$ brought on by the increased tax. The effect of a country 1 tax increase on $f$ is the opposite of that depicted in figure $2 \mathrm{a}$. The tax increase shifts the labour demand schedule downward, moving the equilibrium to the left. We can find $d f / d t_{1}$ by totally differentiating the condition $v(f)=\theta(f)$, yielding

$$
\frac{d f}{d t_{1}}=\frac{-1}{2[\lambda-\kappa(\tau)]}<0 .
$$

It follows from (19) that the steeper the labour-demand schedule (that is, the greater the relative strength of the agglomerative forces) or the flatter the labour-supply schedule (that is, the greater the mobility of labour), the greater is the effect of a tax increase on the allocation of labour across the two countries. Thus, to the extent that it increases either or both agglomerative forces and labour mobility, economic integration makes labour more responsive to tax changes.

Because of the symmetry of the model and the tax game, the tax rates chosen in equilibrium will be the same in each country. Thus, to solve for the equilibrium taxes, we can evaluate (18) and (19) at $f=1 / 2$, set (18) equal to zero, and solve for $t_{1}=t_{2}=t^{N}$. This produces

$$
t^{N}=\lambda-\kappa(\tau)-\frac{1-\mu}{4 \mu} c^{\prime}
$$

where $c^{\prime}$ is the derivative of $c$ with respect to $f$ (see equation 10), or the consumer-price effect. The consumer-price effect enters into $t^{N}$ twice; once in $\kappa(\tau)$, which determines the responsiveness of manufacturing workers to a marginal tax increase, and again in determining the cost to the farmers of the lost manufacturing. $t^{N}$ may be positive or negative.

The most obvious result from (20) is that $t^{N}$ is increasing in $\lambda$. Indeed, if the trade cost were zero, $t^{N}$ would be exactly $\lambda$. As $\lambda$ is a measure of factor immobility, we conclude that 
increased labour mobility intensifies tax competition (that is, lowers taxes) and drives down the welfare of the farmers.

The relationship between the equilibrium tax rate and the trade cost is governed by a linear combination of $\kappa(\tau)$, which is (half) the slope of the labour-demand schedule, and $c^{\prime}$, the consumer-price effect. The net result is a $\mathrm{U}$-shaped relationship between $t^{N}$ and $\tau$, as shown in figure 3. For trade costs below $\hat{\tau}$, taxes rise as the trade cost falls. As $\hat{\tau}>\tau^{*} / 2$ (the minimum tax occurs at a higher trade cost than does the maximum of $\kappa(\tau)$ ), there will always be a range of trade costs over which reductions in $\tau$ simultaneously increase the tax rate and the relative strength of agglomerative forces. It also follows that when the agglomerative forces are at their strongest (that is, labour demand is at its steepest), economic integration in the form of trade cost reductions reduces the intensity of tax competition and equilibrium taxes rise.

This result may be somewhat surprising, but it has an intuitive explanation. The two negative effects of a tax increase in equation (18) (the reduction in the tax base and the reduction in consumer surplus) are greater, the steeper is the labour-demand schedule. Thus, we might expect reductions in trade costs to induce a fall in taxes, at least over the range where the slope of the labour demand schedule is rising. However, a trade-cost reduction does more than just increase the slope of the labour demand schedule. The lower the trade cost, the less costly it is for the farmers to import the goods produced by the manufacturing workers who have fled the tax. So while manufacturing workers are more apt to flee the tax (because of steeper labour demand), the farmers care less if they do (because of the lower trade cost).

Thus we conclude that economic integration, in form of reductions in the trade cost, does not necessarily intensify tax competition. Rather, sufficiently deep integration guarantees that taxes rise. Moreover, economic integration may reduce the intensity of tax competition 
even as it increases the agglomerative forces that make manufacturing labourers more responsive to tax changes.

\subsection{Tax Competition with Concentration}

One might argue that the case studied in the previous section is somewhat special and contrary to the spirit of Krugman (1991a) because, while agglomerative forces are present, no agglomeration actually occurs in equilibrium. In this section, we consider tax competition when $\kappa(\tau)>\lambda$, the labour-demand schedule is steeper than the labour-supply schedule, and thus the only stable outcomes are the concentrated equilibria which produce a core-periphery pattern. This means that, in equilibrium, one country (the core) will have all of the manufacturing workers and all of the tax revenue, while the other country (the periphery) has no revenue and must import all of its manufactures. Given these two extremes, one might expect tax competition to be much more intense. The concern is that to get or to keep the core, a country may have to subsidize manufacturing workers to so great a degree that its farmers end up no better off than those in the periphery.

We will show that, while tax competition with concentration is qualitatively different to that with diversification, it need not result in lower taxes (or greater subsidization) than the diversified case. The concentrated case also produces similar results in terms of the relationship between taxes and trade costs: in that reductions in the trade cost may increase taxes (or reduce subsidies). Indeed, under certain assumptions, we show an even stronger result. If integration causes the labour-demand schedule to become steeper, then it must increase taxes. The intuition is basically the same as in the last section: reducing the trade cost reduces the consumer price differential between the core and the periphery, making it less costly for the farmers when manufacturing workers flee the tax.

To solve the tax-competition game, we begin by examining the effect of taxes on the location of the core. Depending on the taxes adopted in first stage of the game, there may be one or two locational equilibria in the resulting second-stage subgame. This was illustrated in 
figure $2 b$, which showed the maximum tax differential consistent with two locational equilibria (at points $\mathrm{A}^{\prime}$ and $\mathrm{B}^{\prime}$ ). We can solve this maximum tax differential by setting $\theta(0)=v(0)$. This yields the following three possibilities:

i) If $t_{2}-t_{1}>\kappa(\tau)-\lambda$, there is a unique locational equilibrium concentrated in country 1 .

ii) If $t_{1}-t_{2}>\kappa(\tau)-\lambda$, there is a unique locational equilibrium concentrated in country 2 .

iii) If $\left|t_{1}-t_{2}\right|<\kappa(\tau)-\lambda$, concentration in either country is a locational equilibrium.

Let us divide the space of tax pairs $\left(t_{1}, t_{2}\right)$ into three sets, corresponding to the three possibilities listed above: let $C_{1}$ denote the set of tax pairs such that concentration in country 1 is the unique locational equilibrium; let $C_{2}$ be the same for country 2 ; and let $M$ denote the remaining set of tax pairs for which there are two locational equilibria. ${ }^{8}$

Given any foreign tax rate, country $i$ can always guarantee itself the core by creating a large enough tax differential. It particular, it can guarantee itself the core by choosing a tax rate below $\psi\left(t_{j}\right)$ where

$$
\psi\left(t_{j}\right)=t_{j}-\kappa(\tau)+\lambda
$$

and $t_{j}$ is the foreign tax rate. It follows that $C_{1}=\left[\left(t_{1}, t_{2}\right) \mid t_{1}<\psi\left(t_{2}\right)\right], C_{2}=\left[\left(t_{1}, t_{2}\right) \mid t_{2}<\psi\left(t_{1}\right)\right]$, and $M=\left[\left(t_{1}, t_{2}\right) \mid t_{1} \geq \psi\left(t_{2}\right)\right.$ and $\left.t_{2} \geq \psi\left(t_{1}\right)\right]$.

Now that we have determined what locational equilibria can arise from different tax rates, we turn to solving for the subgame-perfect equilibria of the game as a whole. In any such equilibrium, only one country can emerge as the core. Let the tax rate of the core country be $t_{c}$ and that of the periphery be $t_{p}$. Agricultural welfare in the core, $u_{c}^{A}$, and the periphery, $u_{p}^{A}$, can be found by substituting $t_{1}=t_{c}$, and $f=1$ into (16) and (17) yielding,

$$
u_{c}^{A}\left(t_{c}\right)=\left(\frac{1-\mu}{2}\right)\left[\frac{a^{2} n^{2}}{2(1+n)^{2}}+1\right]+t_{c} \mu
$$




$$
u_{p}^{A}=\left(\frac{1-\mu}{2}\right)\left[\frac{(a-\tau)^{2} n^{2}}{2(1+n)^{2}}+1\right]
$$

Because it must import all of its manufactures, the periphery has a higher consumer price than the core. Thus, agricultural workers in the core will typically be better off than those in the periphery, unless the core tax rate is substantially less than zero.

With this in hand, we can state the equilibrium conditions:

Proposition 1: $\left(t_{1}^{*}, t_{2}^{*}\right)$ is subgame perfect equilibrium tax pair if and only if,

(a) $\left(t_{1} *, t_{2}^{*}\right)$ lies in $M$.

(b) $u_{c}^{A}\left(t_{c} *\right) \geq u_{p}^{A}$ (that is, the core is not worse off than the periphery in equilibrium).

(c) $u_{c}^{A}\left[\psi\left(t_{c} *\right)\right] \leq u_{p}^{A}$ (that is, the periphery cannot gain by capturing the core).

(Proof in appendix.)

The necessity of the three conditions in proposition 1 is fairly apparent. Condition (a) says that no country chooses a tax low enough to guarantee itself the core. The reason is that if $t_{c}<\psi\left(t_{p}\right)$, it is always possible for the core to increase revenue with a marginal tax increase without fear of losing the core. Thus, the equilibrium taxes must be such that the workers, and not the taxes, determine the location of the core. Conditions (b) and (c) follow from the fact that a country can always guarantee itself either the core or the periphery with a low- or high-enough tax, respectively. It turns out that these three conditions are also sufficient, as shown in the appendix. In brief, any taxes satisfying these conditions can be supported as an equilibrium by the threat of workers "punishing" countries that "defect" from the equilibrium tax prescription. That is, if a country chooses a tax other than the one specified by the equilibrium, workers punish that country by locating in the other country. ${ }^{9}$

Condition (b) implies that the core country will not subsidize manufacturing workers to the point where the country would be better off as the periphery. This puts a lower bound on the tax rate of the core. Solving $u_{c}^{A}\left(t_{c} *\right) \geq u_{p}^{A}$ gives 


$$
t_{c} * \geq \frac{-(1-\mu)}{4 \mu} c^{\prime}
$$

Condition (c) puts an upper bound on the tax rate of the core. This is because if the core tax rate is too high, then the periphery will be able to capture the core (by setting its tax just below $\left.\psi\left(t_{c}^{*}\right)\right)$ at a tax rate high enough to be profitable. Solving $u_{c}^{A}\left[\psi\left(t_{c} *\right)\right] \leq u_{p}^{A}$ gives

$$
t_{c}^{*} \leq \kappa(\tau)-\lambda-\frac{1-\mu}{4 \mu} c^{\prime}
$$

The set of equilibrium tax rates is shown in figure 4. The two diagonal lines represent $\psi\left(t_{1}\right)$ and $\psi\left(t_{2}\right)$. The area between them is the set $M$. There are two overlapping sets of equilibria, one set in which country 1 is the core and a symmetric set in which country 2 is the core. The country 1 set is bounded above and below by the two horizontal lines representing (25) and (24) respectively. The country 2 set is bounded by the vertical lines.

Consider the effect of economic integration on the equilibrium set in figure 4 . A reduction in $\lambda$ (which is an increase in labour mobility) has no effect on the lower bound (24) and strictly increases the upper bound (25) of the core tax rate. A reduction is the trade cost lowers the consumer price effect and monotonically increases the lower bound on the core tax rate. The upper bound depends on positively on $\kappa(\tau)$ and negatively on $c^{\prime}$. If the trade cost reduction causes the labour-demand schedule to become steeper, then the upper bound unambiguously rises. Hence, the upper and lower bounds on the equilibrium core tax increase as the agglomerative forces become stronger.

To say anything more about the comparative statics of the equilibrium taxes, we must determine which equilibrium will actually obtain. While there are any number of ways one might isolate a unique equilibrium, we propose to following conditions: ${ }^{10}$

\section{Uniqueness Conditions:}

1) For all $\left(t_{1}, t_{2}\right)$ in $M$, workers locate in country 1. 
2) $u_{c}^{A}\left(t_{2}\right) \geq u_{p}^{A}$.

The first condition can be seen as an assumption of inertia on the part of the manufacturing workers. All of the equilibria in the interior of $M$ are supported by the threat of workers fleeing any defecting country en masse, even when remaining in that country continues to be a locational equilibrium. This appears to require an unrealistic degree of coordination on the part of workers as to their locational decisions. In order to play correctly, workers must know not only what the taxes are in each country, but also how all of the other workers are going to respond to these taxes. Perhaps it is more reasonable to assume that if all workers are initially in, say, country 1 , then they will remain in country 1 unless the tax differential is sufficiently large so as to eliminate concentration in that country as an equilibrium. If we make this assumption, then, given any tax by country 2 , country 1 will choose the highest tax that does not cause the core to switch to country 2 . That is, country 1 chooses $t_{1}$ such that $t_{2}=\psi\left(t_{1}\right)$ and retains the core. In figure 4 , this means the equilibrium must lie on the upper frontier of the set $M$.

The second condition states that country 2 (the periphery) should not have an equilibrium tax rate so low that, were it to become the core at that tax rate, it would be worse off than had it remained the periphery. This is simply the application of condition (b) of proposition 1 to both countries (in proposition 1 it applied only to the core, not the periphery). The issue here is that, because it has no workers, the periphery is indifferent between all taxes that do not alter the locational equilibrium. Thus, in some equilibria it may choose a tax so low (negative) that it would never wish to apply that tax to any workers that might come to locate there. This seems unreasonable, and such taxes would certainly be avoided if there were so much as an $\varepsilon$ probability of the core locating in country 2 . In figure 4 , this rules out all equilibrium points to the left of the leftmost vertical line, corresponding to $t_{2}^{*}=-[(1-\mu) / 4 \mu] c^{\prime}$ 
Taken together, our two conditions leave us with a unique equilibrium at point $\mathrm{A}$ in figure 4. At point A, country 1 is the core and charges the highest tax possible. It is the highest possible in the sense that any higher tax would both cause the workers to leave and make it profitable for the periphery to attract the workers. Country 2 is the periphery and charges the tax rate at which it is indifferent between remaining the periphery and becoming the core.

The comparative statics of equilibrium A are straightforward. The tax of the core is equal to the right-hand side of (25). This is decreasing in $\lambda$, and therefore increased labour mobility increases the core tax rate. To understand this, note that the marginal worker in a concentrated equilibrium is the one that most prefers to live in the periphery (though in equilibrium she lives in the core). The core tax is that which makes her indifferent between remaining in the core and moving to the periphery. The less she cares about location per se the higher the core tax she will tolerate before switching countries.

The relationship between the core tax and the trade cost depends positively on $\kappa(\tau)$ and negatively on $c^{\prime}$. Thus, as long as the trade cost reduction increases the agglomerative forces, the core tax unambiguously rises. If the trade cost reduction increases $\kappa(\tau)$, the real wage advantage of the core, the core can charge a higher tax without losing workers. Moreover, the trade cost reduction reduces the consumer price differential between the core and periphery. Holding $\kappa(\tau)$ constant, this increases taxes because the farmers care less about gaining or losing the core. It is straightforward to show that the core tax is inversely related to the trade cost for all $\tau$ whenever $\mu<n /(7 n+4)$. The tax of the periphery is equal to the right-hand side of (24) and thus, as the trade cost falls, it rises monotonically.

\subsection{A Three-Stage Integration Path}

We have seen that with both concentration and diversification, equilibrium taxes may rise as trade costs are reduced. It is also possible that along the path of economic integration there is 
a switch in regimes from diversification to concentration and then back to diversification again, as the trade cost approaches zero. This gives rise to a path of taxes with three distinct stages, such as is illustrated in figure 5 .

Figure 5 plots the results of a specific parameterization of the model. The upper panel shows tax rates, while the lower panel shows the slopes of the labour-demand and supply curves, which determine the nature of the locational equilibria. For high trade costs ( $\tau$ greater than about 0.7 ) the locational equilibrium is diversified and thus the equilibrium tax rate for

each country is $t^{N}$. For mid-level trade costs, between 0.7 and just under $0 \cdot 2$, the locational equilibrium is concentrated in country 1 . The equilibrium taxes that prevail in this region are $t_{1}^{*}$ and $t_{2}{ }^{*}$. For low trade costs, the locational equilibrium becomes diversified again and taxes revert to $t^{N}$.

In the case shown here, the equilibrium taxes for both countries rise as the trade cost falls, for all $\tau$ less than about $0 \cdot 8$. Interestingly there are no discrete jumps in the taxes as the economy switches between regimes. Rather, taxes are continuous along the path, though there is period of divergence between the two countries during the concentration stage. Another aspect of this case is that the taxes are negative for most values of $\tau$. This is due to the extremely high degree of factor mobility $(\lambda=3)$ which is necessary for there to exist a range of concentrated equilibria.

\section{Conclusion}

Regional disparities in income in the context of economic integration can be a serious economic and political problem. The EU, for example, annually spends around 1 per cent of its GNP on subsidies to agriculture and transfers to its "weaker members." While these expenditures may not be necessary to correct disparities caused by integration, it is virtually certain that they are politically necessary for integration to proceed. At the same time, the issue of fiscal harmonisation in the EU has been growing in importance. While this has been 
fuelled mainly by macroeconomic considerations relating to monetary union, the microeconomic case for harmonisation has also been brought to the fore. If economic integration both erodes fiscal autonomy and increases regional disparities, this suggests that fiscal harmonisation and further EU-level subsidies will be called for in the future.

We have shown that economic integration may reduce the intensity of tax competition, thus restoring rather than eroding fiscal autonomy. When the integration takes the form of a reduction in trade costs, this result holds across both classes of equilibria. If labour is quite immobile, then the agglomerative forces may be insufficient to produce a core-periphery pattern. Nevertheless, the presence of those forces in the background produces a U-shaped relationship between taxes and trade costs. The other case is where agglomerative forces are sufficient to produce core-periphery pattern. In that case, the negative relationship between taxes and trade costs is even more robust. The fact that our tax/trade-cost results hold in both cases suggests that this type of analysis has wider application than previously believed in the literature. Venables (1994) and Krugman and Venables (1995) have both argued that geography models are less applicable to multi-country regions (like the EU) than to multiregion countries (like the US), because of the difference in labour mobility. Our analysis suggests otherwise.

About the only case in which economic integration intensifies tax competition in our model is that in which production is diversified and integration takes the form of increased factor mobility. Virtually the entire literature on tax competition is focused around this case (or, more precisely, around the case in which one factor, usually capital, is perfectly mobile). ${ }^{11}$ Our paper shows that by broadening the scope to include core-periphery equilibria or to examine trade liberalization, it becomes more typical to observe a reduction in the intensity of tax competition,

There are number of extensions of the model which are not included in this paper, because of space constraints and because they do not alter the results. One such extension is 
to let the mobile factor be capital, rather than labour. Assuming that individuals may invest their capital abroad without relocating themselves, this would eliminate the home market effect. As the home market effect is one of the agglomerative forces, its absence would make concentrated equilibria less likely, and the diversified case would become the norm. However, there would be no change in the relationship between taxes and trade costs in either case.

Another extension would be to let the trade cost be a tariff. One of the reasons that a reduction in the trade cost leads to an increase in taxation is that the trade cost makes the emigration of workers costly to the farmers (the consumer-price effect). However, if the trade cost were in the form of a tariff, with the revenue allocated to farmers, this logic is called into question. Could it be that emigration increases tariff revenue enough to compensate farmers for the consumer-price effect? The answer is no. Emigration generally reduces tariff revenue in this model, and when it does not, the revenue increase can never compensate for the consumer-price effect. Thus, our results continue to go through for this case.

There are several other potential extensions that we have not considered. For example, we have not allowed for manufacturing workers entering the government objective function. Nor have we allowed for factor substitution in the production technology of manufacturing. Finally, we have not incorporated explicit dynamics in the transitions between equilibria. These extensions await further research.

As a final point, empirical studies have produced no clear consensus on the relationship between integration and fiscal competition. Rodrik (1997) shows that openness (trade divided by GDP) has been associated with decreases in government spending and a shifting tax burden from capital to labour in OECD countries between 1965 and 1992. This suggests that tax competition has intensified. However, Kerchgassner and Pommerehe (1996) show that in the highly integrated but fiscally autonomous cantons of Switzerland, there has been no detectable symptoms of tax competition, even though the locational decisions of high-income individuals are substantially influenced by tax differentials. They conclude that negative fiscal 
consequences from integration in Europe may be minimal. While we do not pretend that our model, in its current form, can reconcile these findings decisively, it is interesting to note that our U-shaped relationship between taxes and the trade cost is consistent with them. OECD countries from 1965 and 1992 were far less integrated with one another than are the cantons of Switzerland. This suggests that the solution to the OECD problem might be to integrate further. 


\section{Notes}

* Drafts of this paper have been presented at the European Science Foundation conference on Migration and Development, Mont Ste-Odile, May 1996; a Workshop on International Trade and Factor Movements between Distorted Economies held by the University of Konstanz, July 1996, the annual meeting of the American Economic Association, New Orleans, January 1997, the Midwest International Economics conference, May 1997, and workshops at EPRU, Copenhagen in July 1997 and the Tinbergen Institute, Rotterdam in November 1997. We are grateful to participants for their comments and suggestions.

1 See Kerchgassner and Pommerehe (1996) for recent empirical work relating to Europe. For a non-technical overview of fiscal issues surrounding economic integration see Tanzi (1995).

2 Krugman and Venables (1995) is closely related to this literature, though it is not strictly speaking a geography model.

3 Krugman considers regions within a country. However, given our interest in government policies to control migration, we re-label the model to have international migration between countries that are part of a common factor market such the EU.

4 All of the countries in the European Union, as well as most of the world, tax individuals on a residency basis. The United States is an exception in taxing its citizens on their global income irrespective of their residency.

5 No results would change if we used an income tax instead of a lump-sum tax.

6 The reason we assume locational preferences is to have a plausible and convenient way of generating an upward-sloping labor supply schedule. There may be other ways to achieve this as well. Anything that causes a location to become less desirable as more laborers move into it, such as congestion costs or rising land prices, will do. None of the results of this paper would be affected by using one of these alternative specifications.

7 Mansoorian and Myers (1993) use a similar specification. See Ludema and Wooton (1997) for implications of alternative distributions.

$8 C_{1}$ and $C_{2}$ are open sets, while $M$ is closed. All three are convex.

9 Proposition 1 also applies to the case in which labor demand and supply have equal slope. Even though there are more than two locational equilibria in this case, the concentrated equilibria continue to exist, and thus a country can still be punished by being made the periphery (which is the worst possible punishment). Likewise, in more complicated nonlinear models like Krugman (1991a), Proposition 1 would apply as long as the concentrated equilibria exist, even though there may be other locational equilibria as well.

10 We have avoided using the standard equilibrium refinements, because most refinements for extensive form games (perfect, proper, sequential, etc.) require finite action spaces. Taxes in our game can take on any value in the real line, and thus the action space is infinite. Moreover, even if we were to modify our game to fit the refinements, they would not produce a unique equilibrium. To get uniqueness, it will always be necessary to impose a restriction along the lines of condition 1.

11 This is not so much a criticism of the tax competition literature as it is a caution against the indiscriminate application of this literature to issues of economic integration. 


\section{References}

Kerchgassner, Gebhard and Werner W. Pommerehe (1996), "Tax Harmonization and Tax Competition in the European Union: Lessons from Switzerland," Journal of Public Economics, 60(3), 351-71.

Krugman, Paul (1980), "Scale Economies, Product Differentiation and the Pattern of Trade," American Economic Review, 70(5), 950-59.

Krugman, Paul (1991a), "Increasing Returns and Economic Geography," Journal of Political Economy, 99(3), 483-499.

Krugman, Paul (1991b), Geography and Trade, Cambridge, MA: MIT Press.

Krugman, Paul (1993), "On the Number and Location of Cities," European Economic Review, 37(March), 293-98.

Krugman, Paul, and Anthony Venables (1995) "Globalization and the Inequality of Nations," Quarterly Journal of Economics CX(4), 857-879.

Ludema, Rodney D., and Ian Wooton (1997), "Regional Integration, Trade and Migration: Are Demand Linkages Relevant in Europe?” CEPR Discussion Paper No. 1656.

Mansoorian, Arman, and Gordon Myers (1993), "Attachment to Home and Efficient Purchases of Population in a Fiscal Externality Economy," Journal of Public Economics, 52, 117-132.

Martin, Phillipe, and Carol Rogers (1995), "Industrial Location and Public Infrastructure," Journal of International Economics, 39(3/4), 335-51.

Oates, Wallace (1972), Fiscal Federalism, New York: Harcourt Brace Jovanovich.

Persson, Torsten, and Guido Tabellini (1992), "The Politics of 1992: Fiscal Policy and European Integration," Review of Economic Studies, 59, 689-701.

Rodrik, Dani (1997) Has Globalization Gone Too Far? Washington DC: Institute for International Economics.

Tanzi, Vito (1995) Taxation in an Integrating World. Integrating National Economies: Promise and Pitfalls Series. Washington DC: Brookings Institution.

Venables, Anthony (1994), "Economic Integration and Industrial Agglomeration," Economic and Social Review, 26(1), 1 - 17.

Wildasin, David E. (1988), "Nash Equilibria in Models of Fiscal Competition," Journal of Public Economics, 35, 229-40.

Wilson, John D. (1987), “Trade, Capital Mobility and Tax Competition," Journal Political Economy, 95(4), 835-56. 
Figure 1. Labour Demand Effects and the Trade Cost

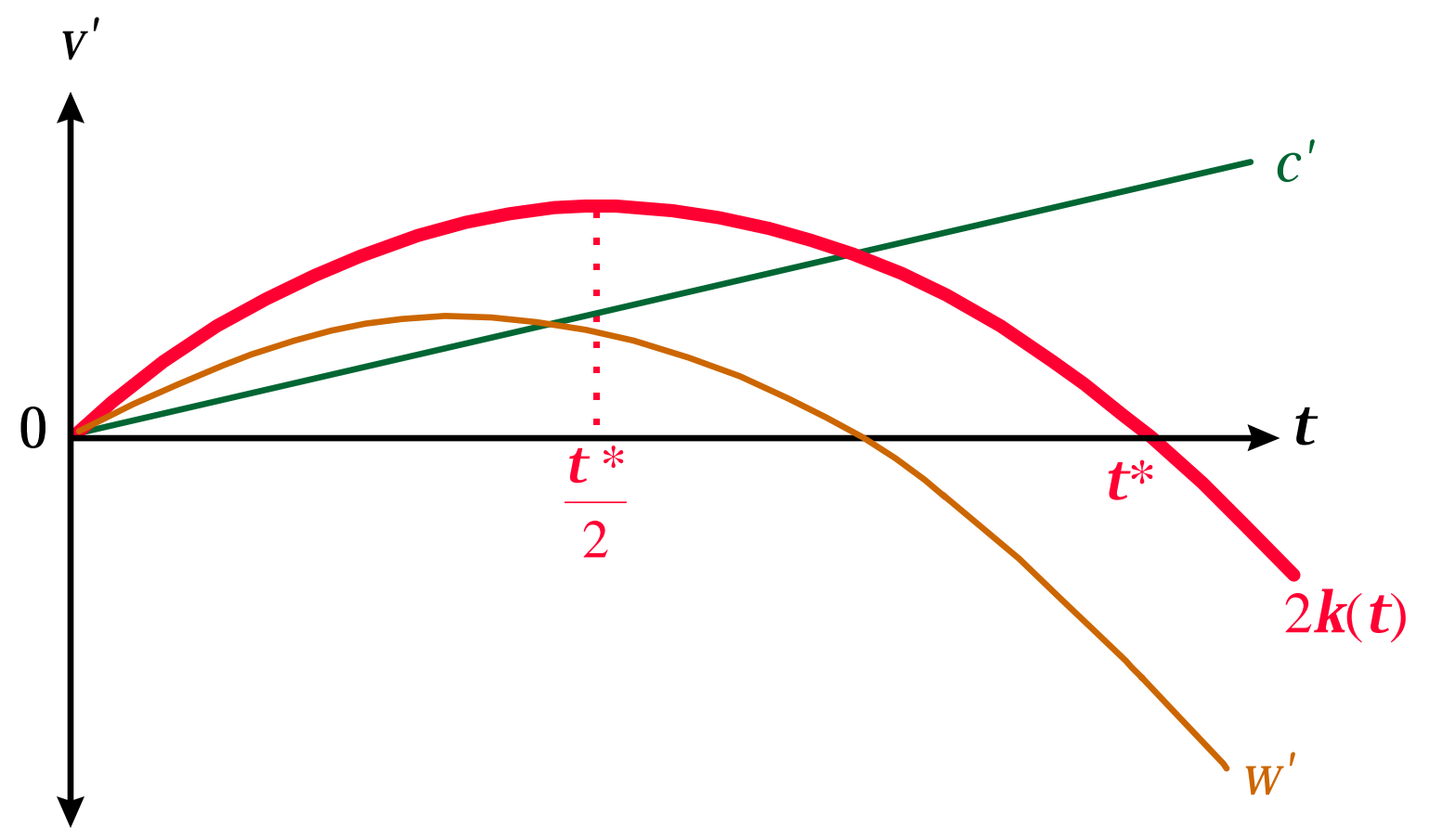

Figure 2a. Diversified Equilibria

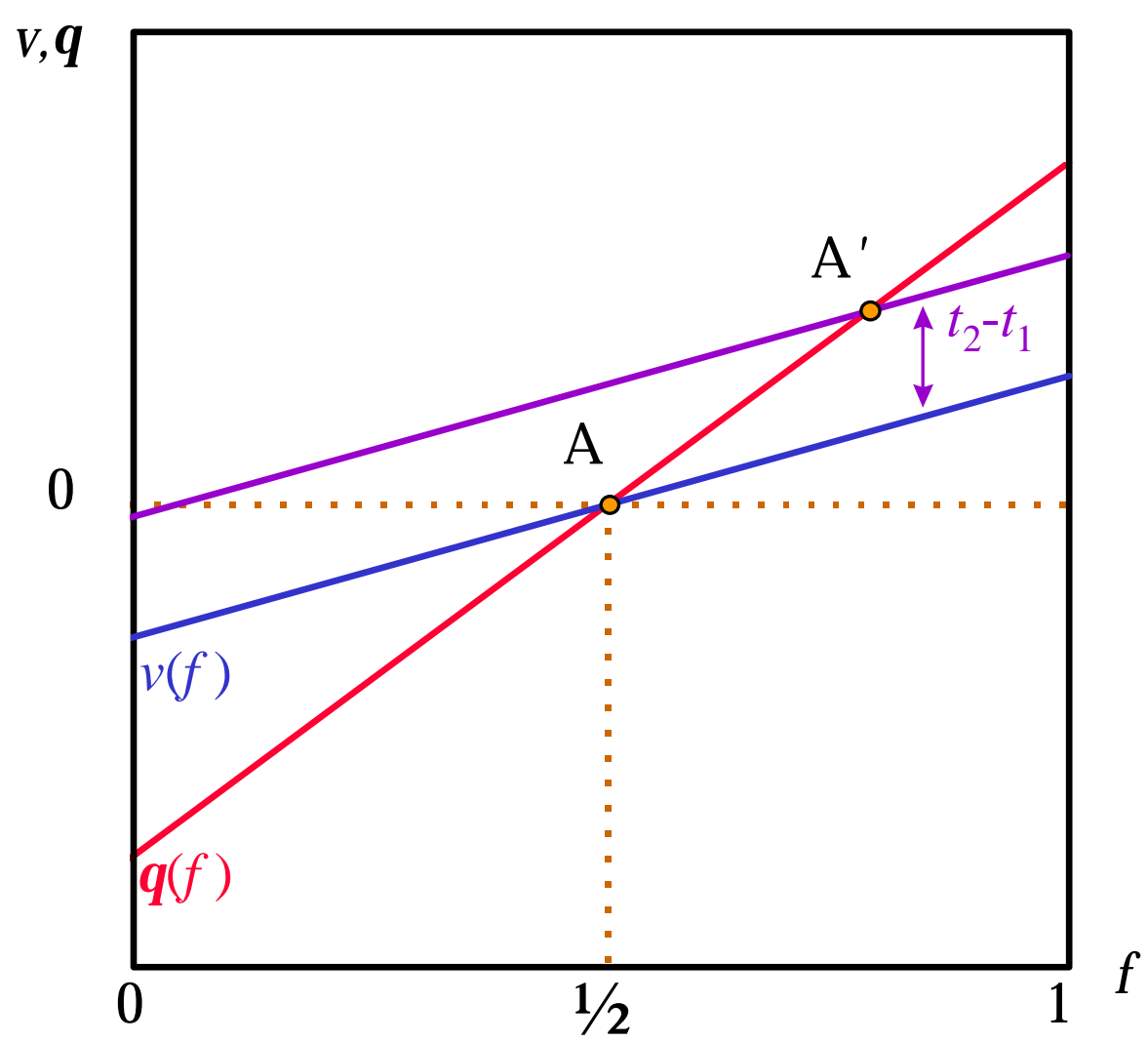


Figure 2b. Concentrated Equilibria

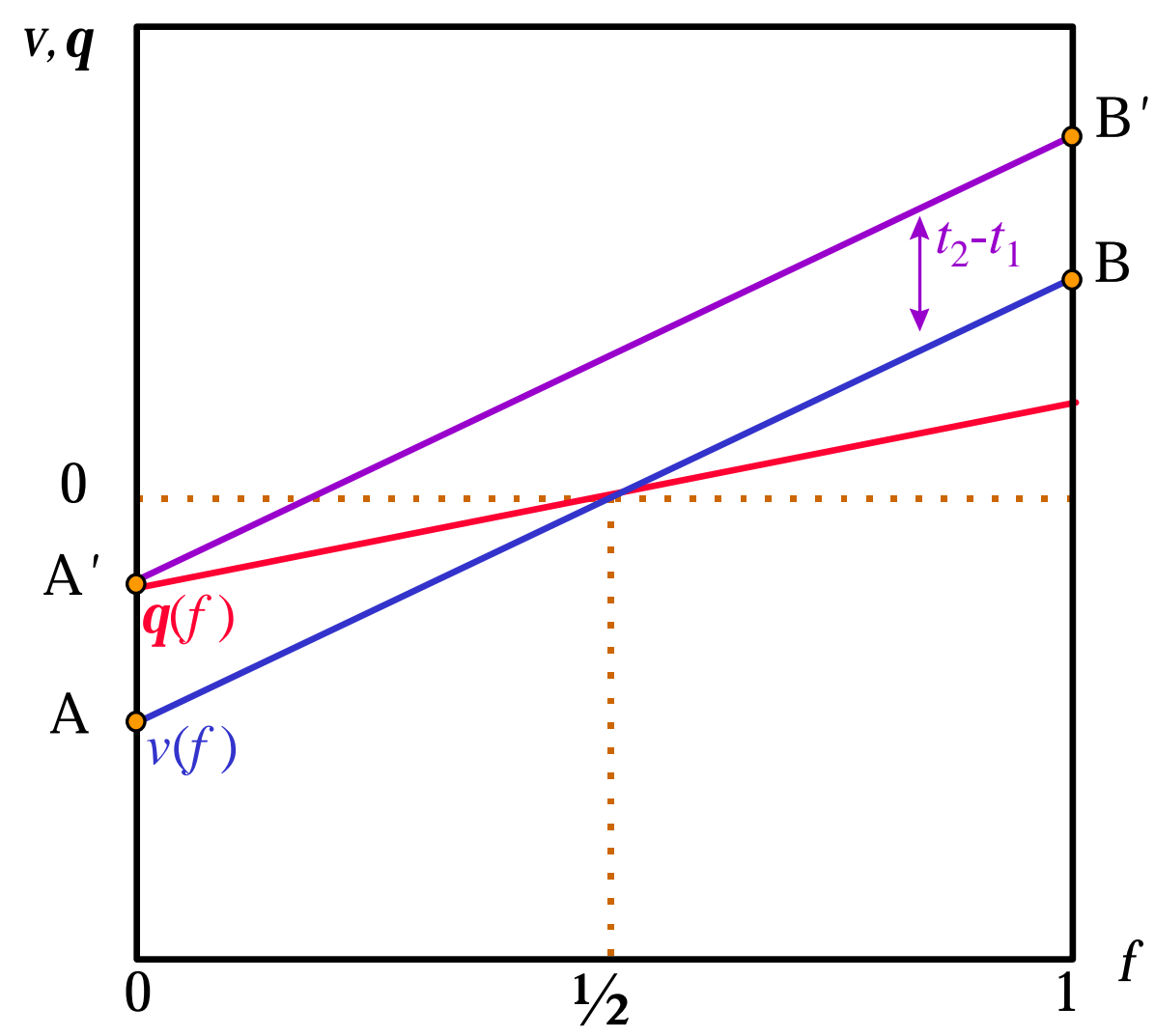

Figure 3. Taxes and the Trade Cost in the Diversified Case

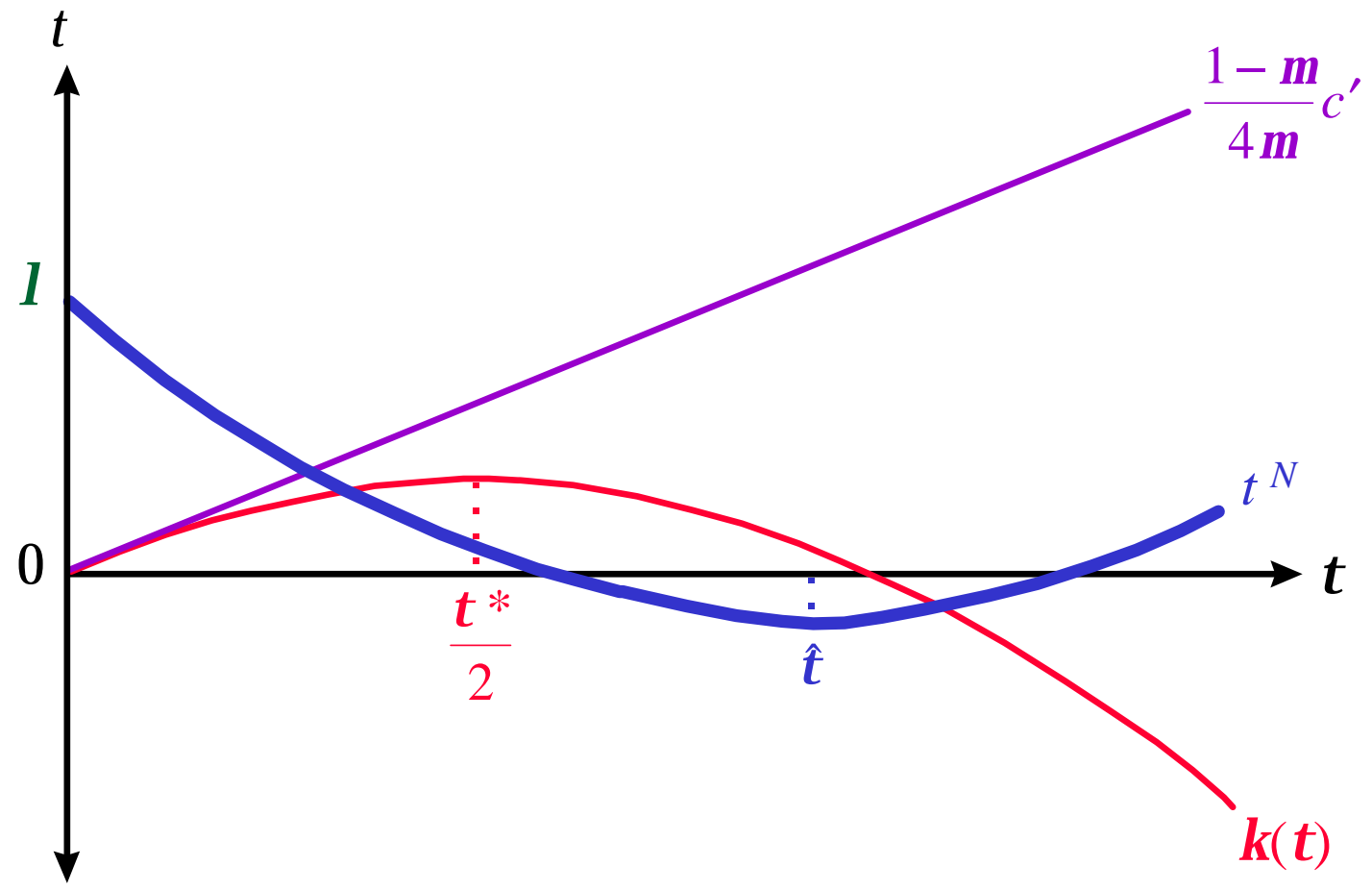


Figure 4. Equilibrium Taxes in the Concentrated Case

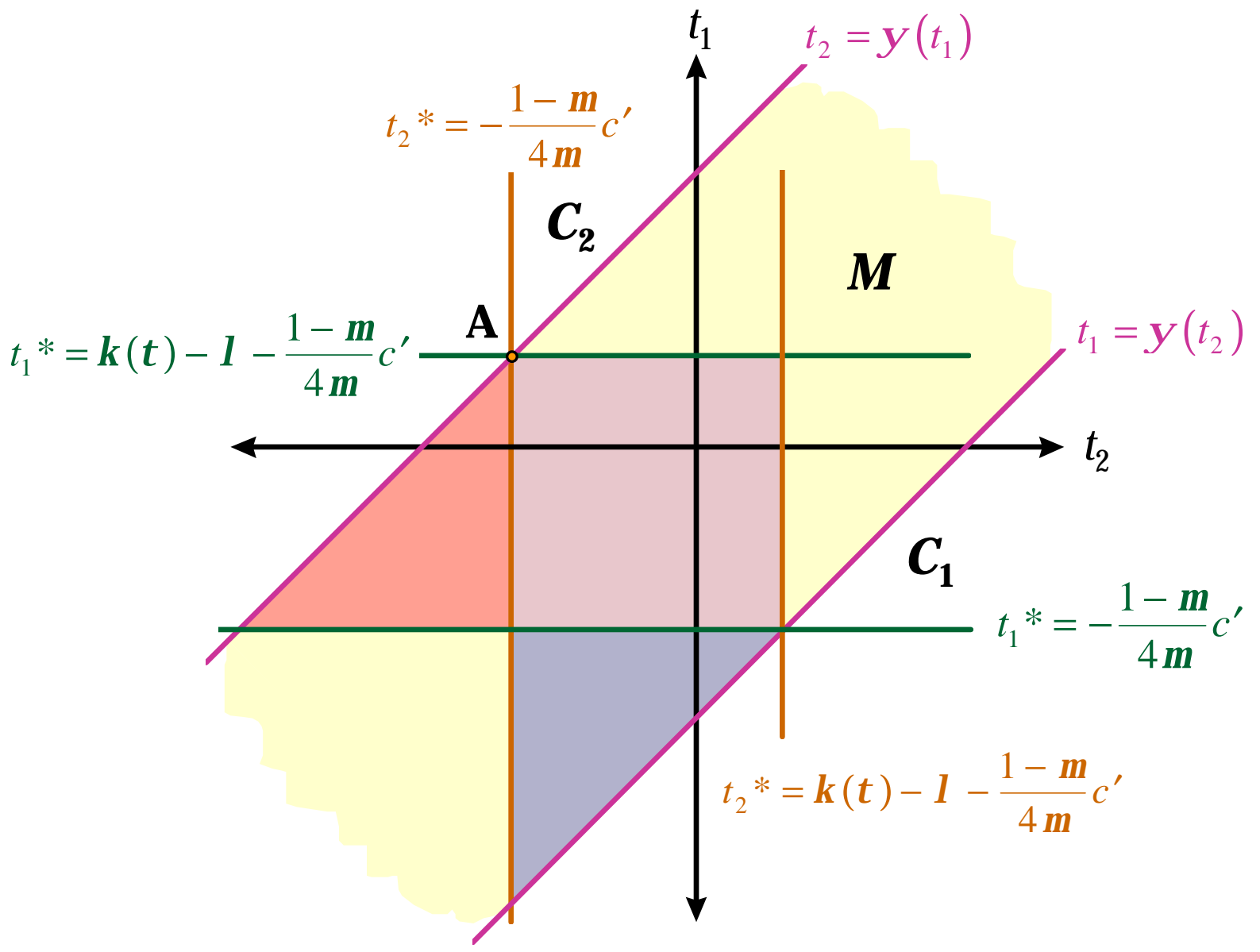

$\square$ Equilibria with Country 1 as Core

$\square$ Equilibria with Country 2 as Core

$\square$ Equilibria with either country as Core 
Figure 5. Equilibrium Tax Rates in 3 Stages of Integration

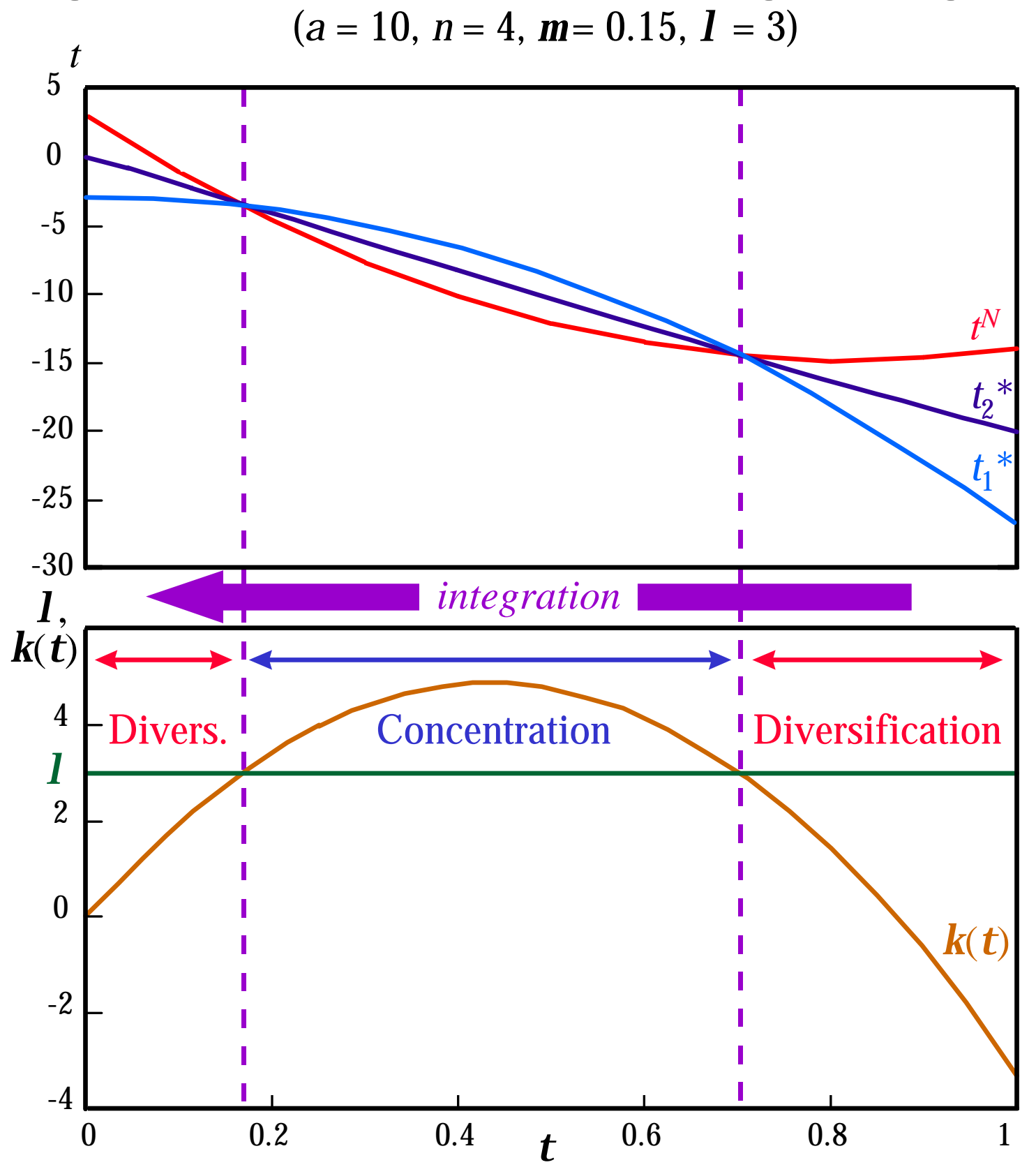




\section{APPENDIX A: Proof of Proposition 1}

The proof is in two steps. First, we show that if any one of the conditions (a), (b) or (c) fails, then $\left(t_{1}^{*}, t_{2}{ }^{*}\right)$ cannot be an equilibrium. Second, we show that if (a), (b) and (c) hold, then it is possible to construct a strategy for the manufacturing workers that would support $\left(t_{1} *, t_{2} *\right)$ as an equilibrium.

Suppose $\left(t_{1}^{*}, t_{2}^{*}\right) \in C_{1}$, in violation of condition (a). Because $C_{1}$ is an open set, the government of country 1 can always slightly increase $t_{1}$ to $t_{1}{ }^{\prime}$, such that $\left(t_{1}{ }^{\prime}, t_{2}{ }^{*}\right) \in C_{1}$, and thereby increase its tax revenue, while continuing to guarantee itself the core. The same would be true of country 2 if $\left(t_{1}{ }^{*}, t_{2}{ }^{*}\right) \in C_{2}$. Thus, no tax pair in $C_{1}$ or $C_{2}$ is immune to deviation. Next consider conditions (b) and (c). Given the tax rate of its opponent, the core can always guarantee itself the periphery, by choosing a high enough tax, and the periphery can always guarantee itself the core, by choosing a low enough tax. Thus, if either (b) or (c) were to fail, then either the core or the periphery would want to deviate from $\left(t_{1}{ }^{*}, t_{2}{ }^{*}\right)$.

Now suppose (a), (b), and (c) hold, and suppose that country 1 is the core in the locational equilibrium induced by $\left(t_{1} *, t_{2} *\right)$ (the case where country 2 is the core is completely analogous). Consider the following response of the manufacturing workers to any $\left(t_{1}, t_{2}\right) \in M$ : if $\left(t_{1}, t_{2}\right)=\left(t_{1}^{*}, t_{2}^{*}\right)$, then all workers locate in country 1 ; if $t_{i} \neq t_{i}^{*}$, and $t_{j}=t_{j}^{*}$, then all workers locate in country $j$ (for $i, j,=1,2$ ). That is, country 1 is the core in equilibrium, but workers respond to deviations from $\left(t_{1}{ }^{*}, t_{2}{ }^{*}\right)$, as long as they are in $M$, by fleeing the deviant country (simultaneous deviations by both countries can be ignored). This is clearly a best response for the workers. Under this worker strategy, any deviation by country 1 (that is, $\left.t_{1} \neq t_{1}^{*}\right)$ such that $\left(t_{1}, t_{2}^{*}\right) \in M \cup C_{2}$ would result in a loss of the core, and this would make country 1 worse off by condition (b). Any deviation by country 1 such that $\left(t_{1}, t_{2}^{*}\right) \in C_{1}$ would maintain the core but involve a reduction in tax revenue. Thus, country 1 would not deviate. For country 2 , any deviation such that $\left(t_{1}^{*}, t_{2}\right) \in M \cup C_{1}$ would result in 
no gain, as country 2 would remain the periphery. Any deviation such that $\left(t_{1}{ }^{*}, t_{2}\right) \in C_{2}$ is ruled out by condition (c). Thus, country 2 would not deviate. Hence, $\left(t_{1}{ }^{*}, t_{2}{ }^{*}\right)$ is a subgameperfect equilibrium tax pair. 


\section{APPENDIX B: Krugman (1991a)}

Krugman (1991a) uses a monopolistic competition specification for the manufacturing sector. All individuals share the same Cobb-Douglas utility function:

$$
U=C_{M}^{\mu} C_{A}^{1-\mu},
$$

where $C_{A}$ is consumption of the agricultural good and $C_{M}$ is an index of consumption of the manufactured good, defined by:

$$
C_{M}=\left[\sum_{\omega \in \Omega} c(\omega)^{\frac{\sigma-1}{\sigma}}\right]^{\frac{\sigma}{(\sigma-1)}}
$$

where $\Omega$ is the set of potential varieties, $c(\omega)$ represents consumption of variety $\omega$, and $\sigma>1$ is the elasticity of substitution between varieties. Using (B1) and (B2), a consumer with income $Y$ will demand a quantity of variety $\omega$ equal to:

$$
c(\omega)=\frac{p(\omega)^{-\sigma}}{\sum_{v \in \Omega} p(v)^{1-\sigma}} \mu Y,
$$

where $p(\omega)$ is the consumer price of variety $\omega$.

Production of the manufactured good involves a fixed input of labour and a constant marginal input:

$$
l(\omega)=a+b x(\omega)
$$

where $x(\omega)$ is output of variety $\omega$ and $l(\omega)$ is the amount of labour used in its production.

There is a large number of manufacturing firms, each producing a single variety and facing demand (B3), the elasticity of which is approximately equal to $\sigma$. Taking this approximation as exact, profit-maximizing firms price their varieties at a constant mark-up over marginal cost. Because all firms within the same country face the same costs, the producer price of any variety produced in country $i$ is:

$$
q_{i}=\left(\frac{\sigma}{\sigma-1}\right) b w_{i}
$$


where $w_{i}$ is the nominal wage rate of workers in country $i$.

Free entry of firms into manufacturing drives profits to zero in equilibrium, and thus

$$
\left(q_{i}-b w_{i}\right) x_{i}=a w_{i}
$$

where $x_{i}$ denotes output of any variety produced in country $i$. Using (B5) in (B6) gives:

$$
x_{1}=x_{2}=\frac{a(\sigma-1)}{b}
$$

Without loss of generality, we choose our costs parameters $a$ and $b$ to be equal to $1 / \sigma$ and $(\sigma-1) / \sigma$, respectively. This implies that $q_{i}=w_{i}, x_{i}=1$, and, from $(4), l(\omega)=1$ for all $\omega$. Thus the number of varieties produced in each country is equal to the number of manufacturing workers living in that country.

Let $e_{i j}$ denote the expenditure of country $i$ on each variety produced in country $j$. It follows from (B3) that the country $i$ 's expenditures are

$$
\begin{gathered}
e_{i i}=\left(\frac{w_{i}}{P_{i}}\right)^{1-\sigma} \mu Y_{i} \\
e_{i j}=\left(\frac{w_{j}}{\tau P_{i}}\right)^{1-\sigma} \mu Y_{i} .
\end{gathered}
$$

for $i, j=1,2$ and $i \neq j$. In (B9), $\tau$ is an "iceberg" trade cost. In both (B8) and (B9), $P_{i}$ represents the price index of country $i$, defined by

and

$$
\begin{aligned}
& P_{1}=\left[f \mu w_{1}^{1-\sigma}+(1-f) \mu\left(\frac{w_{2}}{t}\right)^{1-\sigma}\right]^{\frac{1}{1-\sigma}}, \\
& P_{2}=\left[f \mu\left(\frac{w_{1}}{t}\right)^{1-\sigma}+(1-f) \mu w_{2}^{1-\sigma}\right]^{\frac{1}{1-\sigma}},
\end{aligned}
$$

and $Y_{i}$ is the national income of country $i$ (including agricultural income), or

$$
Y_{1}=\frac{1-\mu}{2}+f \mu w_{1}
$$


and

$$
Y_{2}=\frac{1-\mu}{2}+(1-f) \mu w_{2}
$$

For the manufactures market to clear, it must be that worldwide shipments (consumption plus the amount lost in transit) is equal to one for each variety. An equivalent condition is that worldwide expenditure equals the wage, or

$$
w_{i}=e_{i i}+e_{j i}
$$

Equations (B8) through (B14) make up a system determining wages, price indices, national incomes and expenditures for a given allocation of workers across the two countries. Letting $w=w_{1} / w_{2}, \quad \varepsilon=\left(e_{11}+e_{21}\right) /\left(e_{22}+e_{12}\right), P=P_{1} / P_{2}$, and $Y=Y_{1} / Y_{2}$, we can write the system as,

$$
w=\varepsilon[w, P(w, f), Y(w, f)]
$$

After making substitutions from equations (A8)-(A14), equation (A15) reduces to,

$$
\frac{f}{1-f}=\frac{1}{w}\left[\frac{\left(w^{\sigma}-1\right)\left(1-\kappa^{2}\right)+2\left(\mu \kappa-\kappa^{2}\right)}{\left(w^{-\sigma}-1\right)\left(1-\kappa^{2}\right)+2\left(\mu \kappa-\kappa^{2}\right)}\right],
$$

where $\kappa=\left(1-\tau^{\sigma-1}\right) /\left(1+\tau^{\sigma-1}\right)$. Note that $\kappa$ lies in the interval $[0,1]$ and is a monotonically decreasing function of $\tau$. Thus, we can treat $\kappa$ as a measure of the trade cost.

Let $w(f)$ denote the implicit function satisfying (B16) for all $f$. Its properties are as follows:

\section{Properties of $w(f)$ :}

i) $w(1 / 2)=1$

ii) $w(0)^{\sigma}=w(1)^{-\sigma}=1-2\left(\frac{\mu \kappa-\kappa^{2}}{1-\kappa^{2}}\right)$

iii) $w^{\prime}(f)>0$, for all $f$, if and only if, $0<\kappa<\mu$

iv) $w^{\prime}(1 / 2)=\left(\mu \kappa-\kappa^{2}\right) \Delta$, where $\Delta \equiv 4\left[(\sigma-1)\left(1-\kappa^{2}\right)+(1-\mu \kappa)\right]^{-1}>0$ 


\section{Proof of the Properties of $w(f)$ :}

Properties (i) and (ii) are evident by substitution. Properties (iii) and (iv) require total differentiation of equation (B16). First, we define $\lambda=1-2\left(\frac{\mu \kappa-\kappa^{2}}{1-\kappa^{2}}\right)$. Note that $\lambda$ is always positive, and $\lambda<1$ if and only if $\mu>\kappa$. Using $\lambda$ we can rewrite (B15) as,

$$
\frac{f}{1-f}=\frac{1}{w}\left(\frac{w^{\sigma}-\lambda}{w^{-\sigma}-\lambda}\right)
$$

The terms $w^{\sigma}-\lambda$ and $w^{-\sigma}-\lambda$ must both have the same sign, in order to satisfy (B1). For $w^{\sigma}-\lambda$ and $w^{-\sigma}-\lambda$ to be positive, it must be that $(1 / \lambda)>w^{\sigma}>\lambda$, which implies $\lambda<1$. For $w^{\sigma}-\lambda$ and $w^{-\sigma}-\lambda$ to be negative, it must be that $(1 / \lambda)<w^{\sigma}<\lambda$, which implies $\lambda>1$.

Total differentiation of (B17) gives:

$$
\frac{d w}{d f}=\frac{w}{f(1-f)}\left(\frac{\sigma w^{\sigma}}{w^{\sigma}-\lambda}+\frac{\sigma w^{-\sigma}}{w^{-\sigma}-\lambda}-1\right)^{-1}
$$

As $\sigma>1$, it follows that (B18) is positive if and only if $w^{\sigma}-\lambda$ and $w^{-\sigma}-\lambda$ are positive or, in other words, if and only if $\lambda<1$ (that is, $\mu>\kappa$ ). This proves property (iii). Property (iv) is evident by substitution of $f=1 / 2$ and $w=1$ into (B18).

QED

Let $P(f)=P[w(f), f]$. The relevant properties of $P(f)$ are as follows:

\section{Properties of $P(f)$ :}

i) $P(1 / 2)=1$

ii) $P(0)^{-1}=P(1)=\tau$

iii) $P^{\prime}(f) \leq 0$, for all $f$

iv) $P^{\prime}(1 / 2)=\frac{-\kappa(1-\mu \kappa) \sigma \Delta}{(\sigma-1)}$

\section{Proof of the Properties of $P(f)$ :}


$P(f)$ can be written as,

$$
P(f)=\left[\frac{f w(f)^{1-\sigma}+(1-f) \tau^{\sigma-1}}{(1-f)+f w(f)^{1-\sigma} \tau^{\sigma-1}}\right]^{\frac{1}{1-\sigma}}
$$

Substitution of the appropriate values of $f$ and $w(f)$ into (B19) gives properties (v) and (vi). To establish properties (vii) and (viii), we differentiate equation (B3) with respect to $f$, which gives,

$$
P^{\prime}(f)=\frac{P^{\sigma}}{1-\sigma}\left\{\frac{w^{1-\sigma}\left[1-\tau^{2(\sigma-1)}\right]\left[1+(1-\sigma) f(1-f) \frac{w^{\prime}}{w}\right]}{\left[(1-f)+f w(f)^{1-\sigma} \tau^{\sigma-1}\right]^{2}}\right\}
$$

The right-hand side of equation (B20) is nonpositive provided,

$$
1 \geq(\sigma-1) f(1-f) \frac{w^{\prime}}{w}
$$

Condition (B21) clearly holds if $w^{\prime}<0$ (recall $\sigma>1$ ). Thus our only concern is in case $w^{\prime}>0$, which (from the previous proof, above) occurs when $\lambda<1$. Substituting (B18) into (B21) and rearranging gives,

$$
\frac{w^{\sigma}}{w^{\sigma}-\lambda}+\frac{w^{-\sigma}}{w^{-\sigma}-\lambda} \geq 1
$$

As in the previous proof, $w^{\sigma}-\lambda$ and $w^{-\sigma}-\lambda$ are positive if $\lambda<1$, and thus condition (B22) must also hold. Property (viii) is evident by substitution of $f=1 / 2$ and $w=1$ into (B20).

Finally, let there be an income tax on manufacturing workers, and let $t_{i}$ be the tax rate in country $i$. The after-tax real wage of workers in country $i$ is then:

$$
v_{i}=w_{i}\left(1-t_{i}\right) P_{i}^{-\mu} .
$$

Let $v=v_{1} / v_{2} . v(f)$ is the labour demand schedule. It follows that,

$$
\frac{v^{\prime}(f)}{v(f)}=\frac{w^{\prime}(f)}{w(f)}-\mu \frac{P^{\prime}(f)}{P(f)} .
$$


Thus, labour demand is upward-sloping whenever the relative wage increases with $f$, or whenever $0<\kappa<\mu$. For higher trade costs, labour demand may slope downward, and may not be monotonic. 